\title{
Women's Education in Pakistan: Hidden Fences on Open Frontiers
}

\author{
Dr. Ghazala Noureen \\ Assistant Professor \\ Lahore College for Women University, Lahore, Pakistan \\ E-mail: g_noureen@yahoo.com \\ Dr. Riffat-Un-Nisa Awan \\ Assistant Professor \\ Department of Education, University of Sargodha, Sargodha, Pakistan \\ E-mail: riffatawan@uos.edu.pk
}

\begin{abstract}
Education has been of central significance to the development of human society. The international community's commitment to universal education was first set down in the 1984 Universal Declaration of Human rights. In Pakistan, particularly in rural and sub-urban areas, women are situated largely at the bottom end of the educational system in comparison to their male counterparts. Traditionally, it is assumed that women are limited to their homes and men are the breadwinners of the family. In this situation, education can play a vital role in enhancing the status of women and placing them on an equal footing with their male counterparts and it also increases women's ability to secure employment in the formal sector. The purpose of this study was to understand the importance of education for women in Pakistani society and examine the barriers and obstacles to higher education for women in Pakistan. The sample comprised of ten women from local female university; a vice chancellor, four deans, one head of department each randomly selected from faculties of Natural Sciences, Engineering and Technology, Humanities, Islamic and Oriental Learning and two from Social Sciences (as this faculty comprised 17 departments, much larger than the other three). A case study approach was used and data were collected through semi-structured interview schedule. Participants accepted that there is no doubt that in country like Pakistan women's have to face socio-cultural hurdles to acquire education. It is war against these hidden fences but Pakistani women's are struggling hard to get their rights. Participants identified poverty, dowry, social norms and early marriages as barriers. For most of the participants, societal attitudes towards female higher education are mixed; some people are in favour of female education which is depicted in a participant's personal experience. This study also revealed that education can bring phenomenal change in women's life by enhancing their confidence, raising their status in the family and society.
\end{abstract}

Keywords: Women's education, Hidden fences, Open frontier, Women rights

\section{Introduction}

Women occupied a dominant place in earlier societies before the origin of urbanization. The concept of goddess rather than god is prevalent in ancient societies. As urbanization became more and more flourished the concept of power and military competiveness increased which enhanced male dominance. Due to urbanization society become segregated into different sectors of work classes such as artisan, merchant and agricultural labour. Throughout this era power and authority was exclusively the right of men. All the decisions about family were the right of the family head (male) (Ahmed, 1992). Women do not yet enjoy the same opportunities as men. Their choices as to how to spend their time, in both work and leisure are more constrained than they are for men (Verma, 2006).

Different approaches to mainstreaming the needs and concerns of women in the development agenda emerged from the 1970s onwards, when there was the realization that development and changes in society influence women and men in different ways (David, 1993; Stein, 1997; Radford, 1998; Francis \& Skelton, 2001). This is usually known as Women in Development Approach (WID). The WID framework, with its emphasis on bringing women into development has strong links to the aspects of liberal feminism. It stresses the importance of including women in development planning to improve the efficiency. However this approach ignores the questions of exploitation, subordination and social injustice. In opposition to WID approach, the Gender and 
Development Approach (GAD) emerged in late 1980s (Aikman \&.Unterhalter, 2005). This was a paradigm shift from the "women in development" approach, which focused almost exclusively on women and the impact of macroeconomic policies on their lives, to the "gender and development" perspective. This examines the relationship between the social and economic roles of both women and men across different spheres of life to achieve better living environment for both. This change in perspective led to a parallel shift in data production: from "statistics on women" to "gender statistics," or statistics on women and men in all spheres of life. The WID approach to the challenge of gender inequality in education is to get more girls in schools while GAD approaches have had impact on practice of equality of gender with special emphasis on women's empowerment (Aikman \&.Unterhalter, 2005).

The international community's commitment to universal education was first set down in the 1984 Universal Declaration of Human rights and later reiterated in the 1989 Convention on the Rights of the Child. This commitment again reaffirmed by the world leaders in 1990 at World Summit for Children (Mishra, 2005). The United Nations Millennium Summit in September 2000 focused on the issues of gender inequality and addressed the problem in its two Millennium Development Goals (MDGs)

MDG 2: achieve universal primary education, with the target of ensuring that all boys and girls complete a full course of primary schooling by 2005 (not achieved).

MDG 3: promote gender equality and empower women, with the target of eliminating gender disparities in primary and secondary education by 2005 in all levels of education by 2015 (Aikman \& Unterhalter, 2005). Education is everybody's human right. This simple fact is at the core of UNICEF's commitment to women's education. It means that no girl is to be excluded from school irrespective of their country's situation. There is no acceptable excuse for denying the opportunities to develop her fullest potential. Despite decades of attentions to the issue, some 121 million children are out of school, and 65 million of them are girls (Mishra, 2005).

\section{A Study}

The purpose of the study was to understand the importance of education for women in Pakistani society and examine the barriers and obstacles to higher education for women. A case study approach was used in this study. A case study is an empirical inquiry that investigates contemporary phenomena within its real life context when the boundaries between phenomena and context are not clearly evident; and in which multiple sources of evidence are used. This approach helps to understand a real-life phenomenon in depth (Yin, 2009). The present study was designed to understand the importance of education for women in Pakistani society and examine the barriers and obstacles to higher education for women in Pakistan.

A local female university was taken as a case. The participants for this study were women working in different senior teaching and administrative posts of the university. The focus of the present study was to explore how higher education brings change in women's life. The logic behind this selection was that women working in the same organization share the same job environment and culture, only their family and social background determined how much they were empowered by higher education. The sample comprised ten women; a vice chancellor, four deans, one head of department each randomly selected from faculties of Natural Sciences, Engineering and Technology, Humanities, Islamic and Oriental Learning and two from Social Sciences (as this faculty comprised 17 departments, much larger than the other three). Seven participants were $\mathrm{PhD}$ degree holders and among them five were foreign qualified. Two of the participants were enrolled on a $\mathrm{PhD}$ programme at that time. Participants' age range was from 50 to 60 and they belonged to middle and upper middle class. All participants were married and one of them was divorced.

\section{Results and Discussion}

The formal education system of society is one of the crucial aspects of the social structure- as it acts as an institution, a function and process. The research provides confirmatory evidence that education plays important role in the life women and years of education directly influence the women's life. Women's and role of education in their life is being discussed in subsequent sections.

\subsection{Importance of women's education}

Education has been of central significance to the development of human society. It can be the beginning, not only of individual knowledge, information and awareness, but also a holistic strategy for development and change. Education is a critical input in human resource development and is essential for the country's economic growth. The recognition of this fact has created awareness on the need to focus upon literacy and elementary education programme, not simply as a matter of social justice but more to foster economic growth, social well-being and social stability (Goel, 2004). Women's education is so inextricably linked with the other facets of 
human development that to make it a priority is to also make change on a range of other fronts, from the health and status of women to early childhood care, from nutrition, water and sanitation to community empowerment, from the reduction of child labour and other form of exploitation to the peaceful resolution of conflicts (Mishra, 2005).

In Pakistan, particularly in rural and sub-urban areas, women are situated largely at the bottom end of an educational system in comparison to their male counterparts. Traditionally, it is assumed that women are limited to their homes and men are the breadwinners of the family. Though the constitution of Pakistan (1973) promises equal rights to all citizens, repudiates discrimination on the basis of sex alone and affirms steps to ensure full participation of women in all sphere of life. Since then, the overall participation in education has increased significantly although the pace of change has been slow particularly for women (Qureshi and Rarieya, 2007). Provision of educational opportunities for girls and women has been a part of the national endeavour since independence. According to Haq (2000), "No society has ever liberated itself economically, politically, or socially without a sound base of educated woman". In this situation, education can play a vital role in enhancing the status of women and placing them on an equal footing with their male counterparts and it also increases women's ability to secure employment in the formal sector. Decades of research provide substantial evidence of the link between the expansion of basic education and economic development and women's education has an even positive effect (Mishra 2005). According to one of the participant of the study

Education definitely raises women status whether she contribute in the income of the family or not. She can be at par with men. Majority of the women in our country are uneducated that is why they are suppressed. It is the duty of teachers to tell them [girls] that become a wife is not their ultimate goal. I always teach my students about their worth and importance as a human being. I have a young and new faculty...I have only one message for this young generation.....earch and go ahead. This is not the end of the world.... go and explore opportunities (Head, Fine Arts Department).

Education is considered as value in itself because it leads to the development of the overall personality of the individual. The function of education is to widen the horizon of our experience, as our direct contact with reality is always limited (Nayak and Nair, 2005). Education enables women to perform gainful social roles and enhance their mobility in society. According to Mishra (2005) if educated girls become mothers they are much more likely to send their children to school, thereby passing on and multiplying benefits both for themselves and society in a positive intergenerational effect. Education enabled women to become familiar with problems of home management (Goel, 2004). All over the world, education is regarded as the key factor in overcoming the barriers that women face in life (Mishra, 2005). According to one of the participant,

I am very thankful to God that I am an educated lady. If I did not get education I might be a house wife without any individual recognition ..........spend my life as a wife. I enjoyed my job because I love teaching. If [you] are a working lady your life becomes more disciplined. The house wives life is limited....... usually spends routine life. Now the society is changing due to expansion of education and media. Women never talked about their rights before but now they become more vigilant about their property's right. Women should negotiate on equality basis. It is not necessary that we have to set a battle fields for our rights. We can achieve this target without conflict due to our behaviour. We should negotiate on the basis of equality with solid arguments. This quality can only earn through education. Uneducated woman can't argue (Head, Punjabi Department).

Majority of the participants believed that educated women's are more confident. They can argue and can make their own decision. After getting higher education woman become more useful citizen. They start realizing things and become aware about their rights. They consciously start feeling about their right and if someone tries to overrule their rights, they raise their voice. According to Ram (2004) women's education often proves an instrument of modernization by inculcating new values and liberal ideas in the society. A study in rural Zimbabwe found that among the factors that increased the likelihood of women accessing contraception and antenatal care. In rural Nigeria, 96 per cent of women with secondary and higher education, 53 per cent of those with primary education, and 47 per cent of those with little or no education had sought post-natal care (Kabeer, 2005). A study by Sen in West Bengal noted that educated women were better able to deal with violent husbands: 'access to secondary stages of education may have an important contributory role in enhancing women's capacity to exercise control in their lives through a combination of literacy and numeracy skills, and enhanced self-esteem' (Sen,1999).

In rural Bangladesh, educated women in rural areas participate in a wider range of decisions than uneducated ones. Whereas the latter participated in an average of 1.1 decisions, the number increased to 1.6, 2.0, and 2.3 
among women with primary, middle, and secondary education respectively. (Ref) A study from Tamil Nadu found that better-educated women scored higher than less educated women on a composite index measuring their access to, and control over, resources, as well as their role in economic decision-making. Educated women also appear less likely to suffer from domestic violence. Similar findings were recorded in rural Bangladesh (Schuler et al. 1996). According to one participant of the study,

Higher education brings a lot of confidence among women and increases their income........highly educated........ earning woman makes a difference in her life. The feelings that she is contributing in the family income boost her self-esteem. Her mobility also increased and can go around, can drive her car, can visit her friends and attend some functions (Dean, Art and Humanities).

Although education alone does not always empower girls and women to overcome the tendency to exclude them from the labour market, and continues to play a large role in the reproduction of gender relationships and patriarchal structures, one can argue that education does at least empower women in their domestic and reproductive lives. Studies have shown that the education of women is related, albeit not everywhere nor consistently, to an increase in the demand for child schooling, lower child mortality rates and more effective use of contraception (Jansen, 2006). In Pakistan, highly educated mothers tend to positively affect the life chances of their children (Kazi and Sattar, 1996).

In Pakistani male dominating society education also brings change even in cultural norms of society that is depicted in participant's statements. As one of the participant stated that:

Education gives you a confidence and a sense of self worth. Male members of the family give importance to your opinion and seriously listened to us. If you are not educated they think that you know nothing. Now if I say something everyone valued my saying. They accept my decision. There are some important decisions in the family life for example decision about the marriage of your children. We made all decision with mutual consent and understanding (Head, Punjabi Department).

This study revealed that education can bring phenomenal change in women's life by:

- Enhancing their confidence

- Raising their status in the family and society

- Bring awareness about their rights

- Boosting their self esteem

- Increasing their self efficacy

- Reducing their dependency

- Better up bringing of their children

- Enhancing their mobility

- Opening career opportunities

In fact, the role of women's education in creating and stimulating mass awareness is the prime need of the hour. Women's education alone can successfully negotiate the prevailing ills, whatsoever of a society. It alone can take up the challenge to bring about a real, meaningful and promising revolution in the society (Ram, 2004). But there are some barriers which create hindrance in women's education.

\subsubsection{Gender Inequality in Education}

In recent years, women's education has been high on every donor's agenda, Women's education has been strongly linked to current poverty eradication strategies, with 'gender disparity in primary and secondary education' being taken as an indicator of the 'empowerment' needed to overcome the political, social and economic obstacles that have kept women in poverty (Robinson-Pant, 2004). There are approximately 50 million children are not registered at birth and majority are female, so the lack of birth certificate prevent admission in formal school system worldwide (Verma, 2006).

The continuing prevalence of educational inequality is a major infringement of the rights of women and girls and it is also an important impediment to social and economic development (Verma, 2006). In most developing countries, the private returns to girls' education are usually much lower than the returns to boys' education. The poorer the family, and the more difficult and costly it is for them to send children to school; the more likely girls are to be squeezed out this logic (Gaskell et al.2004; Mishra, 2005). Girl's is more likely to delayed or interrupted by the need to help the family. The significance of the male as the bearer of the family name is also a 
consideration when hard choices are made about who is educated, as is the expectation that the male will be the breadwinner. The role of the women as child bearer is asserted whenever girls are denied education or withdrawn from education (Verma, 2006). The playing field is uneven from the start. Girls are still underrepresented even at primary level in many countries and illiteracy figures for women and girls are unacceptably high particularly in rural areas of the developing countries and amongst newly settled urban populations. Gender stereotyping in the curriculum portrays girls as passive, modest, and shy, while boys are seen as assertive, brave, and ambitious. This reinforces traditional gender roles in society, and acts to limit the kinds of futures that girls are able to imagine for themselves (Kabeer, 2005). One of the shared similar feeling while describing Pakistani context:

Text book analysis of primary and secondary books revealed that in text books women are portrayed as subservient. For example if authors have to portray the environment of home they described that father is sitting on chair reading newspaper, mother is cooking food, daughter is cleaning home and the boy is sitting on the computer. They portray stereotype gender system (Dean, Art and Humanities).

Feminists at this time looked at inequalities in schooling, with girls and women excluded and marginalized in the curriculum, content and practices of education (Weiner, 1997). With their focus on 'equal opportunities' as a key element of progress, liberal feminists in particular placed particular importance on issues of girls' and women's equal access and achievement by subject. The dominant argument during the 1980s was that girls were doing poorly in school and later the workplace because of girls' gendered subject 'choice' with more girls in home economics and languages than sciences and mathematics (Kelly, 1981, 1985). Feminist research also illustrated, however, that despite sexism across every level of schooling, girls were not underperforming at primary school levels in any subject (and were outperforming boys in high school subjects like English (Ringrose, 2007).

The precise consequences of gender inequality in education are different from country to country (Mishra, 2005). Cultural and social beliefs, attitudes and practices prevent girls from benefitting from educational opportunities. These cultural and social beliefs are barriers for girls both in gaining access to formal education and in enjoying the same range of educational opportunity offered to boy. There is often powerful and social rationale for investing in the education of sons rather than daughters.

It is again culture because parents prefer sons. Parents used to think that their old age security is attached to the better income of their sons. Parents during their old age have to live their sons. If son is educated and earn more they have a better future (Dean, Art and Humanities).

It is interesting that discrimination against girls is not confined to developing countries. Although the industrialised world has enjoyed widespread primary and relatively widespread secondary education during this century, there has not been equality of opportunities for girls. In spite of years of active promotion of equal opportunity policies of governments women are still clustered in traditional female subject areas and professions and are underrepresented in science and technology and in higher level research and study (Verma, 2006). According to one of the participant

I am very much convinced that this situation [gender inequality] is not only in Pakistan. I travelled a lot and I think it exists everywhere. If you see historically this is linked with economic and production. When women's were related to production at that time there were women's dominated society. When production came into men's hand the dominance everywhere automatically went to men's hand. The situation is bit grave in developing country like Pakistan because we are locked in poverty cycle (Dean, Natural Sciences).

Early feminist concerns with gender and education, and the feminist drive to eliminate the gender gap, started from the premise that equal access to education would lead to more egalitarian gender relationships. Although some feminist suggests that gender equality, as a goal serves to obscure more complex explanations about the relationship of women to democratic social formations (Arnot and Dillabough 1999). The feminist concerns of the 1970s and 1980s, over the underachievement and marginalization of girls in education defiantly changed the women's education situation especially in the western world. Today, these efforts to 'close the gender gap' are directed more at minority groups and developing countries (Francis \& Skelton, 2001, Ringrose, 2007). Muslim girls are often singled out, which is not surprising given the continuing high rates of illiteracy in Pakistan and several Arab countries (Jansen, 2006).

In our society I must say that if girls do not want to study they are not forced to study (as in the case of boys). If someone daughter is weak in study, parent do not bother much. But if their boys are not interested, it is considered as a calamity of the family. In our society, there are still conventional thinking 
prevailed the role of the boy is to look after the family (bread winner) and ultimate of girl's life is marriage (Head Gender Studies Department).

The recognition that women's equality and rights are central to achieving economic and social priorities is important. But it is not by chance that this has come about. It is the result of work by women's human rights advocates over decades, creating a groundswell of activism for gender equality at global, regional, and national levels (Heyzer, 2005). The manifestation of these efforts occurred when the United Nations Millennium Summit in September 2000 focused on the issues of gender inequality and address the problem in its two Millennium Development Goals (MDGs). The MDGs complement other international declarations on gender equality in education, formulated several years ago but not yet realised: the Beijing platform for action for gender equality (1995), the Dakar Education for All (EFA) Framework of action (2000). Linking MDGs to the implementation of CEDAW and the Beijing Platform for Action is crucial for capitalizing on the synergies generated from both processes. In turn, the resources mobilized for the achievement of MDGs, and international political consensus and commitment to achieve the Goals, can also be used to energize the implementation of CEDAW and the Beijing Platform for Action (Dawood, 2006).. All these efforts focused on elimination of gender disparities at primary level and higher education is still dilemma especially developing countries like Pakistan.

\subsubsection{Limited Access to Higher Education}

Any defence of universal norms involves drawing distinctions among the many things people actually desire. If it is to have any content at all, it will say that some objects of desire are more centred than others for political purposes, more necessary to a human being's quality of life. The social policy was of such nature that many functions that many people over the ages have preferred not to grant women, either not at all or not on a basis of equality. Education of women, even in developed countries, in the initial stages witnessed this treatment. Gender differences and inequality in education with policy favouring more men than women continued even up to three quarters of twentieth century (Gulati, 2006).

The position of women in higher education cannot be treated in isolation from the general status of women in society and from the general aims of economic and social development. Access to education is a telling indicator of women's status in a given society (Verma, 2006). When talking about women's access to higher education it is important to remember that social class has determined at large, the access of girls and women to education along with the kind of education they received.

At that time usually people from upper and educated class joined higher education. It is again culture because parents prefer sons to be educated rather than girl if they have limited resources. Parents used to think that their old age security is attached to the better income of their sons. Parents during their old age have to live their sons. If son is educated and earn more they have a better future. When we talked spending on girls, the main hurdle is dowry. The day girl born parents start collecting dowry (Dean, Art and Humanities).

The most important and common causes are poverty, cost, burden of household labour, shortage of school facilities and negative school environments (Mishra, 2005). In Pakistan according to official statistics 25\% people (actual figure is definitely greater) lived below poverty line. Research participants also mentioned this in their talk about women's education.

The people, whose children can not get higher education, have financial reasons. Majority of the people in our society are still living below poverty line. So investment on one child ...... where family size large......is not possible ....higher education is expensive. We have also some backward areas where due to traditional values parent do not send their girls for education. There is another attitude which exist in smaller portion of the society that girls have so much work........household chores......... caring of younger siblings at home. So they should not waste their time in education because ultimately after marriage they have to do all this (Dean, Social Sciences).

As mentioned by above participant parents considered marriage as the ultimate goal of girls' life. The spread of education in Pakistan among the female sex is inextricably interlinked with the phenomenon of marriage. The fact that a girl's education is not put to direct economic use increases its value as a symbol of wealth and prestige. Her education can be compared to 'a golden bracelet'. It shows that she is from a good family; it enhances her attractiveness and makes her worthy of a good partner. It brings prestige to her father, and to her future husband, and secures her position within the family and, as with a golden bracelet, it is an insurance that can bring an income in difficult times (Jansen, 2006). 
Even in the elite classes girl's education frequently depends on the father's inclination to educate their daughters. Almost all participants shared their experience that they excel in education because their father's were very supportive. Some of the participants' view:

My father usually helped me in studies. My father was very encouraging. My mother was very supportive. My grandmother was not in favour of girl's higher education. She argued with my father that school education is enough for girls. But my father said that I have promised to my daughters. If they got higher grade I would not stop them studying and I don't want to break my promise. It was a type of tussle between my father and his mother (Dean, Art and humanities).

Vice Chancellor of the sampled university shared her experience of interaction with girl's fathers and told father's view about their daughter's education.

........father come for their daughter admission and say that I want she should study home economics. At B.A this subject is just about cooking and embroidery etc. you can learn cooking in two days. I usually asked them why! home economics. They replied ultimately she has to run house if she study this subject she can do well (VC).

In country after country, women hold less than fifty percent of academic and administrative posts in higher education institutions. They are best represented in lower level academic and middle management positions and their participation relative to men decreases at successively higher level (Verma, 2006). There has been a general upward trend in women's participation as university students around the world since 1965, but women remain segregated into 'female' areas and they are still underrepresented among faculty members (Gaskell, 2004; West \& Lyon, 1995).

In spite of the great progress toward gender equity made in recent decades in many countries, women continue to be under-represented at the senior levels in most disciplines (Kurtz-Costes et al. 2006).

In summary, the access of girls and women to educational opportunities continues to be limited at all levels of our educational system, from elementary and secondary school through college and post-graduate programs. Until all residues of these inequalities are eliminated, affirmative measures to level the educational playing field remain critical for women and their families -- and for our nation as a whole, which cannot afford to be deprived of the full potential of half its population.

\subsubsection{Poverty and early marriages}

\subsubsection{Low status of women in society}

It is definitely below in societal hierarchy. Women have accepted this position and they internalised subservient position. It is an Asian patriarchal culture where this behaviour is expected from women. They accept men as highly decision maker. But educated women's can manoeuvre things in a way before men or portray things in a way before men that they make them men to agree with their decisions. Education plays its role whether woman brings income in the family or not. It helps woman to look at things from different angle and to strategise things and puts the things before family in non-confrontational way.

Better educated and earning women are strategic and inspite of secondary position their decisions and polices dominate in the family politics. Educated women's should have to be strategic (Dean, Art and Humanities).

I am sorry to say that in overall society women are not placed in respectable position. Most of the people place women in secondary position. Now it depends upon women how they can change their status. For this they have to become educated and competent. They are struggling and in many cases they are successful. Now transformation is taking place in our society (Dean, social sciences).

Education definitely changes status of women in the family as well as in society (even in Pakistani male dominating society). Until there are no equal opportunities for every member (male and female) of the society, there will be no justice.

In our society I think people respect educated women. Now when ever I travelled on public transport for college (transporters know me as a teacher), they show their respect (Head, Management Sciences).

Education is one of the important factors to break the vicious cycle of women exploitation and bring positive change in their life. The aim of education should be to enhance women competencies regarding different professions depending on their individual aptitude. 
You become empowered if you are educated and earning otherwise earning does not ensure empowerment. In lower class although woman is earning but yet not empowered because she is uneducated. Education should have to enrich women's mind rather than superficial knowledge. After getting this type of education they become more effective member of the society. They come to know how to get their rights (Dean, Social Sciences).

It is evident from the present study that the status and position of women need to be strengthened through wider opportunities for education. Education is an essential instrument of their emancipation and self fulfilment. According to Maslak and Singhal (2008) women pursuit higher education to fulfil their aspirations of self development and confidence. Highly educated women get exposed to new ideas, making them challenge the existing norms and approach behavioural changes more openly than less educated women.

\section{Conclusion}

There is no doubt that in country like Pakistan women have to face socio-cultural hurdles to acquire education. It is war against these hidden fences but Pakistani women are struggling hard to get their rights. Aikman and Unterhalter (2005) stated that we live in a world in which education is characterised by extensive gender inequalities. Two third of all those who have no access to education are girls and women. Over the past two decades, women have made substantial educational progress. Changing expectations of men and women globally will have affected not only their educational and future aspirations, but also the educational opportunities offered to them. According to Maslak and Singhal (2008) important social changes have occurred in the twentieth and twenty-first century which have challenged female identity in middle and upper socioeconomic classes where education is prioritised for both boys and girls. Specifically parental approval of and support for a daughter's aspiration and plan to establish a professional status and career has increased. Basit (1997) had similar findings in her study of educational, social and career aspirations of teenage Muslim girls in Britain where parents were supportive and enthusiastic about their daughter's education and career. It has also been realised in Pakistan it is not possible to keep half of a population economically dependent. Economic targets cannot be met without the participation of women. Girls are now beginning to receive education and people have begun to respect educated women. For most of the participants, societal attitudes towards female higher education are mixed; some people are in favour of female education which is depicted in a participant's personal experience.

These efforts defiantly bring change in the society though slowly. There is a need of collective efforts from all segments of the society to provide wider opportunities of education to women especially belong to low social economic status.

\section{I am a woman and I am very proud of to be a woman........ I believe strongly that I am equally competent ........ equally strong as men (Dean, Natural Sciences).}

These few words uttered by an educated lady tells whole story that how education transform the whole persona and enhance self perception.

In summary, a gender imbalance continues to be the norm in most academic fields, with men occupying the majority of senior-ranked positions and gender parity is not yet the norm. Social, economic and industrial development can be achieved only through expansion of education. Further education must aid national development, not only by developing skills and leadership but also by preparing people for social change covering all instruments of education. Women constitute the most important psychic factor in Pakistani culture and civilization. All traditions and religious beliefs, actually the whole pattern of society draw inspiration from this factor. So, refinement of civilization, gracious living and compassionate behaviour are all transmitted to succeeding generations through women. It is unarguable that no social change can be effected without the active participation of women.

\section{References}

Ahmed, L. (1992). Women and gender in Islam. New York: Yale University.

Aikman, S. \& Unterhalter, E. (2005). The education MDGs: achieving gender equality through curriculum and pedagogy change. Gender and Development, 13:1, 44 -55.

Aikman, S. \& Unterhalter, E. (eds.) (2005). Beyond Access: Transforming, Policy and Practice for Gender Equality in Education. London: Oxfam.

Arnot, M. (2002). Reproducing gender?: Essays on educational theory and feminist. London: Rutledge.

Basit, T.N. (1997). Eastern Values, Western Milieu: Identities and Aspirations of Adolescent British Muslim Girls. Aldershot: Ash gate. 
Batliwala, S. (1994). The Meaning of Women's Empowerment: New Concepts from Action. In Sen, G., Germain. A. and Chen, L. (eds.) Population Policies Reconsidered. Health, Empowerment and Rights. Cambridge: Harvard University Press, pp. 127-38.

Coate, K. (1999). Feminist Knowledge and the Ivory Tower: a case study. Gender and Education, Vol. 11, No. 2, pp. 141-159,

David, M. (1993). Parents, Gender \& Education Reform. London: Black Well Publication.

Francis, B. \& Skelton, C. (eds.) (2001). Investigating gender: Contemporary Perspectives in Education. Buckingham: Open University Press.

Gaskell, J, Eichler, M., Pan,J., Xu, J. \& Zhang, X. (2004). The participation of women faculty in Chinese universities: paradoxes of globalization. Gender and Education, Vol. 16, No. 4.

Goel, A. (2004). Education and Socio- Economic Perspectives of Women Development and Empowerment.

Gulati, S. (2006). Women Education in $21^{\text {st }}$ Century. Jaipur: ABD Publishers.

Hall, C. (1990). Women and Identity: values Choices in a changing World. New York: Hemisphere Publishing Corporation.

Hashemi, S., Schuler, M. \& Riley, A. (1996). Rural Credit Programs and Women's Empowerment in Bangladesh. World Development, 24(4), pp.635-53.

Heyzer, N. (2005). Making the links: women's rights and empowerment are key to achieving the millennium development goals 1. Gender \& Development, 13:1, 9 -12.

Kabeer, N. (2005). Gender equality and women's empowerment: a critical analysis of the third millennium development goal. Gender \& Development, 13:1, 13 -24.

Kazi, S \& Sathar, A. (1996). Explaining Fertility in Rural Punjab: The Role of Gender Development, Paper presented at IUSSAP conference on comparative perspective on fertility transition in South Asia, Rawalpindi, Pakistan, 17-19 December.

Lincoln, Y S. \& Guba, E.G. (1985). Naturalistic Inquiry. London: Sage.

Mahbub-ul-Haq. (2000). Education of Girls and Women. Human Development in South Asia.

Mahbub-ul-Haq. (2002). Human Development in South Asia. Karachi, Oxford University Press.

Malhotra, M. (eds) (2004). Empowerment of Women. New Delhi: Isha Books.

Mamoon, D. (2006). Women's Empowerment through Education. [Online].SDPI Resarch and News Bulletin, Vol. 13, No. 2 \& 3 (March-June 2006).

Maslak, M.A. \& Singhal, G. (2008). The identity of educated women in India: Confluence or divergence. Gender and Education, Vol. 20, No. 5, pp. 481-493.

Mishra R.C. (2005). Women Education. New Delhi: A.P.H Publishing Corporation.

Nayak S. and Nair, J. (2005). Women's Empowerment in India. Jaipur: Pointer Computers.

Qureshi, R and Rarieya, F.A. (eds) (2007). Gender and Education in Pakistan. Karachi: Oxford University Press.

Radford, J. (ed.) (2000). Education, Equality, and Human rights: Issues of gender, race, and sexuality. London: Rutledge.

Ram, S. (eds) (2004). Women Emergence of New Ideology. New Delhi: Common Wealth Publishers.

Ringrose, J. (2007). Successful Girls? Complicating post feminist, neoliberal discourses of educational achievement and gender equality. Gender and Education, Vol. 19, No. 4, pp. 471-489.

Robinson-Pant, A. (2004). Education for women: whose values count? Gender and Education, Vol. 16, No. 4, pp. 473-489.

Sarantakos, S. (1998). Social Research. Sydney: MacMillan.

Stein, J. (1997). Empowerment and Women Health: Theory, Method and Practice. London: Zed Books.

Verma. (2006). Gender, Girls and Women Education. New Delhi: Murari Lal \& Sons.

West, J. and Lyon, K. (1999). T he Trouble with Equal Opportunities: the case of women academics. Gender and Education, V o 1. 7, No. 1.

Yin, R.K. (2009). Case Study Research: Design and Methods. Fourth ed. London: Sage. 